\title{
Los derechos de la niñez: el paradójico contraste entre validez y eficacia*
}

\section{Rights of children: the paradoxical contrast between validity and efficacy}

fecha de recepción: 10 de mayo de 2011

Fecha de evaluación: 20 de junio de 2011

Fecha de aprobación: 21 de junio de 2011

\author{
Misael Tirado Acero, Ph.D.* \\ César Oliveros Ayala, MG.*
}

\section{Resumen}

El presente artículo es un ejercicio reflexivo en torno a las vicisitudes propias de la evolución jurídica y la perspectiva sociológica de los derechos de los niños, niñas y adolescentes. Se desarrolla a partir de tres aspectos: a) un breve recorrido histórico y social de la concepción de niñez; b) las referencias normativas internacionales que han permitido reconocer al niño como sujeto de derechos, y c) las complicaciones actuales para buscar la eficacia de ese ordenamiento jurídico en el entorno social.

Palabras clave: Niñez, adolescencia, derecho, sociología, interés superior, validez y eficacia

\begin{abstract}
This article is a reflective exercise about the vicissitudes of legal developments and the sociological perspective of the rights of children and adolescents. It analyzes three aspects: a) a brief historical and social concept of childhood; b) the international standard references that have allowed recognizing the child as subject of rights and c) the current complications to find the effectiveness of that law system in the social environment.
\end{abstract}

Keywords: Childhood, adolescence, law, sociology, interests, validity and effectiveness

\footnotetext{
* Artículo de investigación.

** Docente T. C. Universidad Militar Nueva Granada. Sociólogo Universidad Nacional de Colombia, con posgrados en Economía y Evaluación Social de Proyectos por la Universidad de los Andes. Doctor en Sociología Jurídica e Instituciones Políticas por la Universidad Externado de Colombia. Investigador en Biopolítica y Biojurídica y Derecho Comparado "Bioetics Group”, y Grupo Liderazgo, Sociedad y Bioética. Departamento de Humanidades, UMNG. Investigador línea de investigación Bioética y Derecho, Derecho Penal y Sociología Jurídica, Grupo Derecho Público, Facultad de Derecho, UMNG. misael.tirado@unimilitar.edu.co; misaeltirado@gmail.com

*** Docente T. C. Universidad Militar Nueva Granada. Abogado de la Universidad Libre, Magíster y Especialista en Docencia e Investigación Universitaria, Candidato a Magíster en Derecho Administrativo. Docente de la Universidad Militar Nueva Granada, en el área de Derecho Público. Experto en Lenguaje Cinematográfico, Guion e Historia del Cine. Cesar.oliveros@unimilitar.edu.co; oliverosaya@yahoo.es
} 


\section{LUKA (Suzanne Vega)}

My name is Luka / I live on the second

floor / I live upstairs from you / Yes I think you've seen me before.

If you hear something late at night / Some kind of trouble, some kind of fight / Just don't ask me what it was / Just don't ask me what it was / Just don't ask me what it was.

I think it's because I'm clumsy / I try not to talk too loud / Maybe it's because I'm crazy / I try not to act too

proud.

They only hit until you cry / And after that you don't ask why / You just don't argue anymore / You just don't argue anymore / You just don't argue anymore.

Yes I think I'm okay / I walked into the door again / Well, if you ask that's what

I'll say / And it's not your business anyway / I guess I'd like to be alone / With nothing broken, nothing thrown.

Just don't ask me how I am / Just don't ask me how I am / Just don't ask me how I am.

My name is Luka / I live on the second floor / I live upstairs from you / Yes I think you've seen me before.

If you hear something late at night / Some kind of trouble, some kind of fight / Just don't ask me what it was / Just don't ask me what it was / Just don't ask me what it was.
They only hit until you cry / And after that you don't ask why / You just don't argue anymore / You just don't argue anymore / You just don't argue

anymore.

\section{INTRODUCCIÓN}

En 1987 Suzanne Vega, la intérprete norteamericana de música pop, hizo famosa una canción que se posicionó como un clásico de dicho género: Luka. Su letra, bastante sencilla, enfoca uno de los temas que siempre ha formado parte de la convivencia social: el maltrato infantil dentro del marco de la violencia intrafamiliar.

Esa canción es el testimonio sutil del sufrimiento de un niño que advierte a su nuevo vecino la necesidad de no hacer nada, no comentar, ni siquiera preguntar cuando llegue a escuchar algún tipo de pelea, riña o golpes, en el apartamento del segundo piso donde él vive. Es la declaración triste de un chico que se autoinculpa del maltrato doméstico que recibe. "They only hit until you cry, and after that you don't ask why" ("Ellos solamente te pegan hasta que lloras, y después no preguntes por qué") son frases hacia el final de la canción, que revelan tangencialmente la identidad de esos "castigadores".

La letra deja entrever un drama intenso, cargado de agresiones, de prohibiciones, de omisiones, que circunscriben la vida de un niño para quien la soledad se ha convertido en su mejor compañera con el fin de alejarse del caos que vive a diario, en tanto la palabra destrucción ha invadido su existencia.

Luka no concibe que alguien desee $-y$ puedaayudarlo, y afirma reiteradamente que eso no es asunto de otros, que tal vez merece lo que le pasa porque es "torpe", "habla muy alto", "está loco" o "actúa con soberbia", frases marcadamente 
dicientes sobre la inserción de la violencia psicológica, esa forma de disminuir al ser humano en sus deseos, en su dignidad, y que muchas veces es más perjudicial y deja mayores cicatrices que la corporal.

El cuestionamiento sobre el mensaje de la canción permite diversas interpretaciones; puede pensarse que Luka es introvertido a raíz de los golpes que recibe, o bien tiene una participación activa y directa en el deseo de aislarse (pues a su juicio podría estar protegiendo a personas que se atrevan a indagar la situación que afronta), ora considerar que son pruebas merecidas y que debe y puede soportar; en fin, todas las ideas que inspira desembocan en las constantes preguntas que rodean el tema en su dimensión social:

¿Cuál es la validez de la violencia física sobre un ser humano?

\section{¿Corregir equivale a castigar?}

¿Puede invocarse el principio de autoridad para infligir castigos físicos a un menor de edad?

Estos y otros tantos interrogantes surgen frente a ese tipo de comportamiento que se manifiesta en el propio entorno familiar y, a su vez, se deriva de una tergiversada acepción de la autoridad parental, cuando se extralimita el poder transformándolo en una amenaza para la convivencia y cuando los propósitos educativos, formativos y de protección se desdibujan, dando cabida a una amalgama de comportamientos que subvierten la dignidad humana.

Pues bien, parafraseando la máxima que ha identificado al Principito de Saint-Exupéry, y en respuesta a esa idea de la superficialidad, el tema es tan esencial que se hace invisible a los ojos...

El presente artículo es un ejercicio reflexivo sobre las connotaciones socio-jurídicas que han dado lugar a otorgar el carácter de prevalencia a ese conjunto de derechos propios de los niños, niñas y adolescentes dentro de un marco de validez normativa internacional, sustentada en la Convención sobre los Derechos del Niño (1989), así como la brecha que se ha abierto en consonancia con el paradigma de eficacia inserto en la práctica del derecho.

\section{UNA VISIÓN HISTÓRICA DESDE LO SOCIAL}

En la actualidad, los Derechos del Niño se han erigido como una institución jurídica prevalente y significativa para la sociedad occidental en procura de establecer el reconocimiento y protección de aquellas personas consideradas punto nodal en la construcción del porvenir.

Pese a que no ha sido fácil la inserción de tal criterio en la visión cultural de los pueblos, su devenir abonó el terreno para que logre consolidarse como un indicador de avances sociales.

En el contexto internacional, pareciera que el conjunto de fines sobre la materia propugnara por afianzarse con marcada intención, por parte de los gobiernos, en el marco de escenarios como conferencias, simposios y foros multilaterales. No obstante, es otro de los tantos temas que terminan configurándose como objeto de soft law', en virtud de los niveles de eficacia que logran apreciarse.

Sin embargo, la temática se niega a perder vigencia, sobre todo en Estados como Colombia donde, a diario, la niñez es subvalorada.

A lo largo de la historia de la humanidad, ese carácter del infante que hoy conocemos bajo el tamiz de la prevalencia en el derecho ha tomado diferentes caras y su mutabilidad interpretativa, incluso desde lo social, es más que abundante.

1 Tremolada Álvarez, Eric. (2004). Vicisitudes del derecho internacional. Universidad Externado de Colombia. El soft law se define como el conjunto de decisiones aparentemente jurídicas que adolecen de fuerza obligatoria y surgen en escenarios políticos. 
En realidad, la historia de la niñez se halla escasamente documentada; ese ámbito de derechos que, en la actualidad, es referente interpretativo en un rango de superioridad resulta novedoso. Apenas si se vislumbran algunos historiadores como pioneros en la investigación del tema.

Tal es el caso de Philippe Ariès, quien publica $E I$ niño y la vida familiar en el antiguo régimen, en el año 1960, obra que se convierte en el primer punto de partida para tratar la temática más allá de las meras estadísticas².

La preocupación que les asiste a los investigadores sobre la infancia se delimita en dos tendencias investigativas:

a. La reconfiguración de la concepción de infancia desde enfoques variados como: historia de la vida privada, historia de las mentalidades, historia como psicogénesis, etc. ${ }^{3}$.

b. Los procesos psico-pedagógicos de génesis de la concepción de infancia, desarrollada en tres vertientes (la revolución sentimental, derivada del naturalismo pedagógico, que considera a los menores aislados de la vida social; movimientos en favor de la escolarización total de la infancia vinculados a los sistemas generales de educación, y la pedagogía y la psicología como soportes para orientar de manera científica la conducta infantil) ${ }^{4}$.

Aclarados los anteriores postulados, la obra de Ariès "se propone descubrir cómo la actitud de los adultos respecto a la infancia se ha transformado a través del tiempo, estableciendo una relación entre la historia de la educación y la historia social" ${ }^{5}$;

2 Zoila, Santiago Antonio, (2007). Los niños en la historia: Ios enfoques historiográficos de la infancia. En revista Takwá, 11 - 12, pp. 31. México: UNAM.

3 Ídem, p. 32.

4 Ibídem; citando a María Victoria Alzate Piedrahíta, "Concepciones e imágenes de la infancia" y "El 'descubrimiento' de la infancia: historia de un sentimiento", en Ciencias Humanas, Colombia, Nos. 28 y 30, 2001 (www.utp.edu.co/ chumanas).

5 Ob. cit., 33. arguye que la educación es un factor trascendental para definir la identidad infantil en la medida en que se ocupa del aprendizaje enfocado a deslindar el mundo de los niños del de los adultos ${ }^{6}$.

Posteriormente, surge la obra de Lloyd De Mause, intitulada Historia de la infancia, en la cual se sustenta la teoría psicogénica de la historia: "estipula que la fuerza central del cambio histórico de la infancia no es la tecnología ni la economía, sino los cambios psicogénicos de la personalidad resultado de las interacciones entre padres e hijos"7.

\section{Dicho autor expone que}

[...] las concepciones de la infancia están asociadas a las formas de crianza, las cuales se conciben como un tipo de relaciones paterno-filiales. De Mause establece seis tipos de relaciones paternofiliales: 1) infanticidio (antigüedad-siglo IV), 2) abandono (siglos IV-XIII), 3) ambivalencia (siglos XIV y XVII), 4) intrusión (siglo XVIII), 5) socialización (siglo XIXmediados del XX) y 6) ayuda (se inicia a mediados del siglo XX) ${ }^{8}$.

Vale la pena recorrer algunos de los conceptos nodales que Ariès y De Mause identifican para establecer una especie de historiografía de la niñez, con el ánimo de presentar ese panorama desde el cual el derecho comienza a advertir la necesidad de validar conductas preventivas y atender a los requerimientos sociales -que no familiares- de los infantes.

Ariès enfoca sus planteamientos doctrinales desde el marco histórico del antiguo régimen" "cuando la infancia no se consideraba un periodo especial de la vida, los niños disfrutaban de una situación privilegiada, ya que podían mezclarse con perso-

6 Ob. cit.

7 Ob. cit

8 Ob. cit.

9 Conjunto de costumbres e instituciones políticas y económicas afincadas en Francia y en Europa hasta finales del siglo XVIII; http:// thales.cica.es/rd/Recursos/rd99/ed99-0257-01/aregimen.html 
nas de distintas clases y edades, lo que indudablemente les proporcionaba enormes posibilidades de aprendizaje no formal"10.

Más adelante, en los inicios de la época moderna, la entronización del concepto de infancia "[...] como un periodo de la vida diferente al adulto, cuando el niño pierde esa libertad de la que disfrutaba anteriormente, viéndose sometido a la tiranía familiar"11", genera una visión completamente absolutista del ejercicio de autoridad parental ${ }^{12}$, desconociendo cualquier posibilidad de interacción entre el adulto y el niño. En contraste con la Edad Media, en la que no existía el concepto de infancia propiamente dicho, significó, al menos, el reconocimiento de una condición y etapa del ser humano, pues ni siquiera en las artes se procuraba representarle; los artistas "eran incapaces de pintar un niño salvo como un hombre en menor escala"13.

Entonces, la estimación que se tenía del infante convergía en interpretarle como un ser en condiciones de fragilidad, cuando no podía responder ni valerse por sí mismo; en el momento en que dejaba la dependencia tenía la posibilidad de incluirse en la comunidad adulta y compartir actividades y juegos ${ }^{14}$. Acorde con Ariès, había un periodo al que llama mimoseo, "que se corresponde con los primeros años de la vida en el que el niño era considerado como un personaje gracioso y, por tanto, recibía un tratamiento y consideración especial”15.

Desde el entorno familiar, se reglaba la libertad de los niños "imponiéndoles serios controles

\footnotetext{
10 Ochaíta Alderete, Esperanza y otra. (2004). Hacia una teoría de las necesidades infantiles y adolescentes: necesidades y derechos en el marco de la Convención de las Naciones Unidas sobre los Derechos del Niño. Madrid, España: McGraw - Hill, p. 16.

11 Ídem, p. 17.

12 Quiceno Franco, Gloria Inés y Oliveros Aya, César. (2009). Ius corrigendi: una garantía de protección y formación. Bogotá: Universidad La Gran Colombia.

13 Ochaíta, p. 17.

14 Ibídem, p. 17.

15 Op. cit.
}

de disciplina, e incluso utilizando como práctica habitual los castigos severos, tanto físicos como psicológicos" ${ }^{\prime \prime 16}$, bajo el entendido de que influían las tradiciones como marco toral para la concreción de objetivos como "la conservación de los bienes patrimoniales, la práctica de un oficio común y, en los casos de crisis, la protección del honor e incluso de la vida"17; más adelante, en la época moderna, "la familia delegaba gran parte de sus funciones en la escuela, lo que supondría, a juicio de este autor, un debilitamiento de las relaciones afectivas entre sus miembros" ${ }^{\prime \prime}$.

En el marco de la Edad Media, en síntesis, el niño

[...] era considerado como un adulto pequeño, hacía parte del engranaje de una sociedad y se educaba para ser adulto, para ayudar a conservar el grupo social. Al desintegrarse esa cohesión, se vuelca la mirada al sujeto individual. Dentro de esa concepción empieza a configurarse el niño como sujeto, como ser real capaz de percibir el mundo de una manera diferente a la del adulto ${ }^{19}$.

Lloyd de Mause contradice a Ariès, señalando que los artistas medievales sí tenían representación de figuras infantiles: "lo que se ha producido a lo largo de la historia es una evolución de las reacciones que muestran los adultos con respecto a los niños, niñas y adolescentes ${ }^{\prime 20}$, situación que le permite argüir que, en consecuencia, han existido tres tipos de reacciones:

Las reacciones proyectivas, mediante las cuales los padres utilizan al niño como vehículo para proyectar los contenidos de su propio inconsciente. Estas proyecciones hacen que, a veces, se considerase al niño como un ser maldito, lo que tiene como consecuencia el desarrollo de prácticas como la fajadura, las suje-

\footnotetext{
Op. cit.

Op. cit.

Op. cit.

http: www.educacioninicial.com

Op. cit.
} 
ciones, o la invención de personajes siniestros para atemorizarle ${ }^{21}$.

En efecto, "no podríamos hablar de una falta de cariño de los padres hacia sus hijos, sino más bien de una incapacidad afectiva para concebir al niño como una persona distinta de ellos mismos"22.

En otra modalidad,

Las reacciones de inversión, mediante las cuales los padres utilizan al niño como sustituto de una figura adulta importante en su propia infancia. Como consecuencia de este tipo de reacciones se establecerían prácticas como los castigos físicos aplicables a la corrección de la conducta de los niños, con el objetivo de que estos alcanzasen la perfección, según recomendaban los moralistas reformadores ${ }^{23}$.

Finalmente,

La reacción empática, que supone la posibilidad del adulto de experimentar empatía respecto al niño y sus necesidades $y$, en consecuencia, de actuar de manera adecuada para satisfacerlas. Ejemplos de prácticas asociadas a este último tipo de reacción serían la introducción de los cursos escolares de acuerdo con los niveles infantiles, o el reconocimiento de la necesidad de afecto $^{24}$.

Teniendo en cuenta dichas ideas, el autor propende por la elaboración de

[...] una teoría psicogenética de la historia, en la que postula que el origen de los cambios históricos no está ni en la tecnología, ni en la economía, sino en los cambios psicogenéticos de la personalidad resultantes de las interacciones entre padres e hijos en sucesivas generaciones. $\mathrm{O}$, dicho en otros términos, en las modificaciones que se producen en las pautas de relación que se establecen entre padres e hijos, fundamentalmen- te como consecuencia de las reacciones que manifiestan los adultos ante la presencia de los niños y de los cambios que se producen en las pautas de crianza a lo largo de diferentes periodos históricos" 25 .

Esta fundamentación doctrinal da un claro sentido de prevalencia a la infancia para justificar, incluso, las vicisitudes históricas que definen a cada época.

De Mause arguye que:

Dado que la estructura psíquica ha de transmitirse siempre de generación en generación a través del estrecho conducto de la infancia, las prácticas de crianza de los niños de una sociedad no son simplemente uno entre otros rasgos culturales. Son la condición misma de la transmisión y desarrollo de todos Ios demás elementos culturales e imponen límites concretos a lo que se puede lograr en todas las demás esferas de la historia. Para que se mantengan determinados rasgos culturales se han de dar determinadas experiencias infantiles, y una vez que esas experiencias ya no se dan, los rasgos desaparecen ${ }^{26}$.

Así las cosas, en el tránsito del siglo XVII al XVIII se construye un nuevo concepto de infancia y un poco más adelante (a mediados del XVIII) el de adolescencia, donde autores, como el alemán Dietrich Tiedeman (1787), crean una nueva disciplina denominada psicología del niño.

En el siglo XX, la infancia y la adolescencia

[...] se convierten en etapas fundamentales para el desarrollo de la persona, que se alargan considerablemente en el tiempo, y en las que se deben interiorizar una serie de hábitos, normas y conductas que posteriormente van a permitir a esa persona integrarse y participar plenamente en su sociedad ${ }^{27}$. 
Ello conlleva a que los caracteres propios de cada etapa supongan una legitimación social, y se enfoquen a la implementación de cuidados y protección permanentes ${ }^{28}$.

Pero este postulado no fue inmediato, se ha ido estableciendo de manera progresiva, pues a inicios del siglo XX cabe destacar el avance de la psicología cognitiva en consonancia con el psicoanálisis para dar lugar al denominado desarrollo evolutivo, lo que permite volver la atención al infante para descubrirle, para ahondar en su comportamiento, para entenderlo y posicionarlo como esa fase primigenia y de mayor importancia del ser humano, toda vez que en ella se consolida el carácter, la personalidad y la proyección de sus etapas futuras, siendo conscientes de su propia historia ${ }^{29}$.

Empero, la práctica social distaba mucho de aquellas orientaciones, pues los avatares económicos fueron ocasionando un estancamiento en la consideración del niño como propiedad; un ser inferior obligatoriamente supervisado y controlado por los adultos, lo que fue generando una actitud pasiva y conformista $^{30}$ que aún subyace en el inconsciente colectivo. Ello se traduce en la explotación laboral que todavía pervive para millones de niños, niñas y adolescentes.

Es insólito e innegable que

[...] en América Latina, las niñas y los niños trabajan mayoritariamente en el sector informal de la economía, con frecuencia invisibilizados en talleres caseros de reparación, en la producción artesanal de bienes de consumo, como vendedores ambulantes en las calles, o bien en los basureros recolectando desechos $^{31}$.

\footnotetext{
28 Op. cit.

29 http: www.educacioninicial.com

30 Ídem.

31 Ibídem.
}

\section{INSTRUMENTOS JURÍDICOS EN PRO DE LA INFANCIA Y LA ADOLESCENCIA}

En el proceso de estructuración jurídica de la época moderna, el infante no se consideró sujeto de derechos hasta entrado el siglo XIX cuando empezó a estimarse el denominado estatuto de minoridad, en la medida en que el rol del Estado se transforma hacia la protección de sus ciudadanos, surgiendo preocupaciones como acoger a huérfanos y abandonados. De igual forma, se proyecta hacia la elaboración de normas enfocadas en garantizar el estudio obligatorio, la atención en salud, la salvaguarda frente al maltrato y vedar el trabajo obligatorio ${ }^{32}$; sin embargo, dicho estatuto contiene privaciones a los derechos como la igualdad, la libertad y la seguridad ${ }^{33}$, pues la familia $y$, en un rol suplente, el Estado lo consideraban un ser dependiente con múltiples limitaciones, incluso en la perspectiva de su desarrollo y comunicación.

Por supuesto, el deber ser jurídico termina con una desastrada fundamentación de validez y una endeble caracterización de eficacia; por ejemplo, la adopción y la protección pública, mecanismos derivados de la respuesta estatal a la solución de desigualdades, no sirvieron para paliar la subvaloración del infante.

En principio, la adopción no se estimó como posibilidad de satisfacer las necesidades de los niños, sino una vía para resolver el problema de las familias sin hijos. Por otro lado, la protección pública terminó convirtiéndose en un instrumento para mantener la sociedad a salvo de los menores abandonados quienes, en últimas, se categorizaban como una variedad de delincuentes.

En el siglo XX por fin surge la preocupación de legislar para los infantes, pero solamente hasta

32 Ochaíta y Espinosa, op. cit., p. 427.

33 Op. cit. 
el año 1989 se entenderán como sujetos activos de derechos.

Desde tal enfoque, en 1924 aparece la primera estructura normativa, la Declaración de Ginebra, aprobada por la V Asamblea General de la Sociedad de las Naciones, inspirada en los trabajos de Eglantyne Jebb (creadora de la organización Save the Children, destinada a la ayuda y asistencia de niños víctimas de la Segunda Guerra Mundial y de la Revolución Rusa).

Esta normatividad se enfoca a plantear parámetros que puedan servir como condiciones adecuadas para el desarrollo físico; la alimentación como base fundamental de desarrollo; la atención médica en tanto garantía para la preservación de la salud; un conjunto de cuidados especiales para el tratamiento de niños con deficiencias, los de difícil adaptación, los huérfanos y los abandonados; la protección en situaciones de emergencia, y la salvaguarda contra cualquier modalidad de explotación.

Otro campo que aborda pretende definir el alcance de la autonomía como ser humano, indicando algunas condiciones para el desarrollo espiritual en clara coincidencia con una posición de fijación psicológica de los tópicos conductuales diferentes a los de un adulto.

El texto normativo no resulta lo suficientemente claro para tenerlo como un referente jurídico efectivo, adolece de concreción filológica que dificulta el ejercicio hermenéutico y no pasa de ser un antecedente para lograr respuestas eficaces en el contexto social.

Luego, en 1959, la Asamblea General de las Naciones Unidas profiere la Declaración de los Derechos de los Niños, organizada en un preámbulo y diez principios, los cuales se categorizan como sigue:
- Protección especial en concordancia con leyes que den prioridad al interés superior del niño.

- Desarrollo pleno en condiciones de libertad y dignidad.

- Derecho a un nombre y a una nacionalidad.

- Derecho a la alimentación, vivienda, recreo y atención sanitaria.

- Derecho a cuidados y atenciones especiales en caso de impedimento físico, mental o social.

- Derecho a tener una familia que proporcione amor, seguridad y comprensión.

- Derecho a educación gratuita y obligatoria en las fases elementales.

- Derecho al juego y a la recreación.

- Derecho a ser atendidos prevalentemente en situaciones de emergencia.

- Derecho a ser protegido contra cualquier modalidad de abandono, crueldad y explotación.

- Derecho a ser protegido contra cualquier forma de discriminación racial, religiosa o de otra índole.

Posteriormente, la Convención sobre los Derechos del Niño, del año 1989, retoma el concepto del interés superior del niño, sustentado en la declaración antecedente. Esta nueva disposición, aprobada por la Asamblea General de las Naciones Unidas el 20 de noviembre,

[...] puede considerarse el primer tratado universal y multilateral que considera al niño como sujeto de derechos y no como objeto pasivo del derecho a ser protegido. En este caso, se trata de un convenio o ley internacional que tiene carácter vinculante para todos los Estados que lo han ratificado, que en la actualidad son todos los del mundo, exceptuando Estados Unidos y Somalia ${ }^{34}$.

La Convención desvirtúa la idea del infante como sujeto sin derechos y le da una especial posición en la sociedad, entendiéndolo como ciudadano en desarrollo.

$34 \quad$ Op. cit., pp. 431 - 432. 
El artículo $1^{\circ}$ especifica la edad en la que se enmarcan los conceptos de niñez y adolescencia, esto es, entre los cero y dieciocho años; el artículo $2^{\circ}$ fundamenta la no discriminación y la satisfacción de necesidades básicas; el artículo $3^{\circ}$ entraña la base primordial para la legitimación de derechos: el interés superior del niño. Por consiguiente, se clasifica e identifica el rango de prevalencia para el reconocimiento progresivo y secuencial de derechos en el orden que se menciona a continuación:

- Derecho a la dirección y orientación de padres y madres.

- Derecho a la supervivencia y desarrollo.

- Derecho al nombre y a la nacionalidad.

- Derecho a la preservación de la identidad.

- No separación del padre y la madre.

- Reunificación familiar.

- No sufrir retenciones o traslados ilícitos.

- Expresar la opinión en los asuntos que le afecten.

- Libertad de expresión.

- Libertad de pensamiento, conciencia y religión.

- Libertad de asociación.

- Protección a la vida privada.

- Acceso a la información adecuada.

- Ser criado y educado por ambos padres.

- Ser protegido contra los malos tratos.

- Protección del Estado para los niños privados del medio familiar.

- Derecho a la adopción.

- Derechos de los niños refugiados.

- Derechos de los niños impedidos.

- Salud y servicios médicos.

- Evaluación periódica del internamiento (para salud física o mental).

- Seguridad social.

- Nivel de vida adecuado.

- Educación.

- Educación adecuada al desarrollo integral.
- Derechos de los niños pertenecientes a poblaciones indígenas.

- Descanso, esparcimiento y juego.

- Protección contra la explotación en el trabajo.

- Protección del uso de estupefacientes.

- Protección contra la explotación sexual.

- Prevención contra la venta y tráfico de niños.

- No ser sometido a tortura o privación de libertad.

- No participar en conflictos armados.

- Derecho a la recuperación e integración social.

- Derechos relativos a la administración de justicia de menores.

- Derecho a que se respeten las normas vigentes más favorables a los niños.

Por supuesto, la entronización de esta normatividad es significativa mas no lo suficientemente eficaz; su proyección hacia el futuro se ralentiza debido "a la globalización de la economía y al neocapitalismo liberal que dominan el orden económico internacional y que son incompatibles con la satisfacción universal de necesidades humanas básicas" ${ }^{\prime 35}$, todo ello aunado a la ausencia de poder legislativo y ejecutivo de los organismos supranacionales que abogan por los derechos humanos, que imposibilita hacerlos exigibles e imperativos, amén de las brechas diferenciales entre países pobres y ricos ${ }^{36}$.

\section{LA VALIDEZ JURÍDICA -Y LA PROGRESIVA EFICACIA- DE LA CONVENCIÓN SOBRE LOS DERECHOS DEL NIÑO}

En el caso particular, Colombia es un país que pese a ratificar los protocolos internacionales en materia de DH y DIH, entra en controversia con los parámetros sobre la participación y el protagonismo infantil en materia de los DH de la niñez y la ado-

$35 \quad$ Op. cit., p. 439.

36 Op. cit. 
lescencia. Es precisamente la Convención sobre los Derechos del Niño (1989) el instrumento normativo internacional que, de una manera transversal, empieza a colocar pilares y consolidar acciones en pro de un mundo apropiado para los niños y las niñas, en el que su autorrepresentación y voz propia es una lucha constante bajo la estimación de protagonistas principales.

Histórica y socioculturalmente, la niñez ha sido invisibilizada, minusvalidada, estigmatizada, carente de competencias; tradicionalmente en el discurso y actuar de nuestros padres o abuelos, esta etapa de la infancia y la niñez correspondía a la del silencio absoluto, en el cual los mayores o el mundo adulto hablaba y los menores escuchaban. Los niños y las niñas eran depositarios de saberes, y permanecían bajo una costumbre tutelar y paternalista. Nuestra cotidianidad ha cambiado por la trascendencia cultural y por los soportes que en materia constitucional hoy gozan los Estados nación. En nuestra Carta Política, los derechos de los niños son primero, "[...] prevalecen sobre los derechos de los demás", y son vistos como sujetos titulares de derechos, dándoles cabida dentro del concepto de ciudadanía plena que el mundo adulto, después de veinte años, aún no ha asimilado por completo.

Estas normas positivas enmarcadas en el derecho, al contrastarlas con la realidad social, dejan entrever vacíos de tipo jurídico y político, al priorizar realmente lo normado por parte de los operadores que se ciñen a lo establecido en los códigos y no toman en cuenta las realidades problemáticas, las necesidades apremiantes; mientras que para lo social las realidades van más allá de lo jurídico, contemplando una relación vinculante con las esferas políticas, económicas, culturales, contextuales, demográficas, entre otras.

En el sustrato de estas falencias, un discurso que se queda rezagado a la realidad de la niñez, la infancia y la adolescencia, es el de la perspectiva de género. Pese a que se viene impulsando desde el sistema de Naciones Unidas, desde las entidades nacionales de cooperación y los distintos entes nacionales hace algunas décadas, la situación particular es preocupante ya que se siguen quebrantando los derechos de los más vulnerables y no hay garantías suficientes y la debida protección como responsabilidad primigenia del Estado. Actualmente, en todo proyecto que se ejecute con el sistema de Naciones Unidas, la contraparte debe tener en cuenta la perspectiva de género, basado en las mismas reivindicaciones del movimiento social de las mujeres en el mundo y de consabida lucha por las transformaciones socioculturales de la no violencia basada en género.

Los cambios necesitan ajustes y sobre todo tiempo, decantación, asimilación, y este es un proceso en el que han tomado protagonismo diferentes estamentos sociales, políticos, económicos... aunando esfuerzos, sensibilizando, concienciando y transformando realidades. De esta manera se busca establecer como política pública que las necesidades y los intereses de las mujeres y en especial de la niñez, la infancia y la adolescencia, se reconozcan y operativicen en las distintas instancias de intervención social.

Sabemos que los Derechos Humanos han surgido con el tiempo como mecanismos vinculantes y garantes del ser humano en su interacción social y en respuesta a sus necesidades individuales, grupales o colectivas. Esta lucha por el reconocimiento de derechos parte de las necesidades particulares en una realidad y un contexto concretos y de allí se establecen nexos entre ese presente, su pasado y su proyección al futuro; por ende los Derechos Humanos tienen un espacio temporal histórico con el que evolucionan.

Así, los antecedentes de los modernos derechos fundamentales, los encontramos en tres antiguos sistemas nacionales: inglés, del siglo XVII (en el que se proclaman el Acta de Habeas Corpus de 1679 y el Bill of Rights de 1688, y cuyo 
precedente originario está en la Carta Magna de 1215); americano (pudiendo destacar la Declaración de los derechos del buen pueblo de Virginia de 1776, junto a la Declaración de Independencia de los Estados Unidos de 1776); y francés (cuyo texto primordial es la Declaración de los Derechos del Hombre y del Ciudadano de 1789) ${ }^{37}$.

De igual modo, en este transcurrir histórico, los derechos humanos se van internacionalizando y especializando cada vez más, acorde con problemáticas puntuales y realidades sociales en las que cada sociedad es dinámica, cambiante, ya que aporta y construye desde sus hechos o fenómenos sociales, los cuales nos aportan y nos nutren en la interacción y corresponsabilidad como Estados Nación. En palabras de Talcott Parsons, podría afirmarse que la sociedad no puede ser totalmente abierta ni totalmente cerrada, ya que si fuese abierta, nos fusionaríamos con nuestro entorno; y por el contrario, si fuese cerrada, nos aislaríamos y no nos podríamos comunicar. Necesitamos de interdependencias y de vasos comunicantes, dando paso a lo que se gesta en el interior de cada sociedad, lo cual permite nutrir, extrapolar y ampliar progresivamente los mismos derechos.

\begin{abstract}
Así se ha llegado a hablar de derechos cada vez más sofisticados, como los que se conocen bajo el rubro de derechos de la solidaridad (derecho al desarrollo, a la paz, a un medio ambiente sano) ${ }^{38}$.
\end{abstract}

Con el paso del tiempo, los logros en tal sentido han sido significativos, sin perjuicio de lo que todavía falta a nivel político, económico, social y cultural. Las mujeres siguen avanzando en sus demandas, y las entidades, por mandato internacional, deben ir acogiendo sus reivindicaciones, sumándose a ello el debate de la participación

37 Curso Sistema Interamericano de Derechos Humanos. p. 4. Instituto Interamericano de Derechos Humanos. San Juan de Costa Rica. Mayor información: http://www.iidh.ed.cr

38 Ibídem. y el protagonismo de la infancia, la niñez y la adolescencia bajo su propia voz y representación.

Por consiguiente, tal contexto ocasiona que el tema de las mujeres esté más cercano a las organizaciones sociales y a las entidades y estructuras comunitarias no gubernamentales. A pesar que no se ha logrado entronizar en la cotidianidad y el quehacer institucional como bastión de fondo, no es menos cierto que hace presencia crítica, a guisa de un llamado de atención permanente.

Ahora, tras las demandas de los y las menores de edad como sujetos de derechos y conscientes de su ciudadanía, se abre una nueva posibilidad de lucha, ya que se identifican líderes que permean su sistema social, teniendo peso no solo como individuos sino como colectivos que se consolidan y catapultan en su interior y en la sociedad en general (adulta), conllevando proceso reflexivos para construir, deconstruir, reconstruir su propia realidad social desde su autonomía, haciendo uso efectivo de las libertades fundamentales. Entre ellas, la opinión, la expresión y la asociación, principios que no necesariamente van en contravía de lo establecido en el mundo adulto o en el statu quo adultocéntrico.

La no materialización de esta perspectiva, ni su incorporación completa en las lógicas organizativas y en las políticas institucionales de las entidades sociales o públicas, se debe a que, aparte de las resistencias culturales al respecto, no se tiene claro cómo incorporar el protagonismo y la participación de los y las menores de edad, sumado a la ambigüedad en la aplicación, monitoreo y evaluación de la perspectiva de género como política pública. Esto influye en el papel que debe asumirse respecto a lo que serían las necesidades y los intereses, pero desde la mirada cautelosa del mundo adulto.

Al adentrarse en la sociología de la niñez, el respeto de las opiniones del niño o de la niña es una tendencia que se ajusta a lo establecido en 
la Convención de los Derechos del Niño y que los Estados parte (excepto Estados Unidos y Somalia) han ratificado.

Los niños y las niñas, como sujetos de derechos, son una esponja que absorbe y reproduce todo lo que ven o escuchan; por ello es tan importante ese habitus primario (en términos de Pierre Bordieu), esa primera etapa de socialización, donde se establezcan pautas claras y precisas que correspondan con las prácticas y comportamientos que se asumen en calidad de adultos. Toda acción debe estar acorde con lo que se les transmite y no con el doble lenguaje en el que suele caerse, lo cual refleja contradicciones, genera conflicto y desvía sus actos como sujetos "en condiciones de formarse un juicio propio".

\begin{abstract}
Es necesario seguir trabajando para garantizar la participación activa de los niños y su intervención en todas las decisiones que los afectan en las familias, la escuela y la vida de la sociedad, habida cuenta de los artículos 12, 13 y 15 de la Convención [...] Estos principios deben reflejarse en todas las políticas y programas relativos a los niños. Debe insistirse en la concienciación del público en general, incluidas las comunidades tradicionales, los dirigentes religiosos y los programas educacionales, sobre la aplicación de estos principios ${ }^{39}$.
\end{abstract}

En Colombia, la formulación de políticas públicas, las decisiones de los tribunales, la ejecución de programas se piensan desde el mundo adulto $y$ es una lucha constante de la niñez y la juventud por tener voz propia, por buscar ser escuchados en todos los asuntos que los afectan, teniendo en cuenta sine qua non la edad y la madurez, su derecho a ser escuchados, incluso en procedimientos judiciales o administrativos que los afectan directa o indirectamente. Por tanto, el Estado, en cabeza

39 Manual de Aplicación de la Convención de los Derechos del Niño, p. 177 "La CDN no se pronuncia a favor de la imposición de una edad mínima para conocer o tener en cuenta las opiniones del niño", p. 178. de sus tribunales y órganos oficiales, debe facilitar la participación del niño con los medios adecuados (cámara de Gesell), un lenguaje menos técnico o elevado, etc.

Las ideologías pesan en las estructuras sociales ya que estas ejercen contrapeso al cambio. Desde una mirada sociológica, existen tres campos de ideas: las decadentes, las prevalentes y las emergentes ${ }^{40}$. Las ideas decadentes ocupaban espacios centrales en la vida social, y pese a ser obsoletas aún mantienen adeptos que se resisten al cambio; podríamos ejemplificar con el adagio popular "la letra con sangre entra", que denota castigar al niño para educar al hombre bajo una doctrina correccional, en la que no se puede ser bondadoso con el menor de edad. Las ideas prevalentes son las que enmarcan una vigencia o centralidad en el periodo histórico en el que vivimos, y los movimientos sociales lo mueven al escenario social de lo público, que coloca al niño como actor principal y como sujeto de derechos dando paso a la protección integral. El tercer ámbito, de ideas emergentes, conlleva un cambio social pese a las resistencias del adultocentrismo, siendo valoraciones que toman en cuenta innovaciones políticas, socioculturales, y que coloca en el primer plano a la niñez y a la adolescencia como protagonistas.

La forma combinada de estos diversos sistemas de ideas configura indeterminados esquemas y patrones sociales para con la infancia, por ejemplo patrones de crianza, de conducta, de educación, de cuidados de salud y la vida, de participación y organización, de desenvolvimiento en la familia, en la escuela y la comunidad ${ }^{41}$.

La carga ideológica imbuida en la sociedad no es ajena al sistema jurídico cuyos operadores se muestran renuentes al cambio, desinformados o con prevenciones, al tener que salirse del esquema

\footnotetext{
40 Jorge Enrique Bazán. Modo de vida de la infancia. pp. 27-28.

41 Ibíd. p. 28
} 
técnico como tomadores de decisiones y administradores de justicia.

Siguiendo a Bazán, es importante tener en cuenta las particularidades de la población de menores de edad; consecuentemente, no todos son iguales ni se pueden medir con el mismo rasero, ya que el modo de vida "es la forma como se desenvuelve, produce, y reproduce la vida [...] material y espiritual de la infancia"42. Esto obedece a diferentes ámbitos de socialización, identidades particulares y significados diferentes o iguales basados en las mismas costumbres, prácticas, normas, representaciones e imaginarios que ese grupo contextual tiene, sin la necesidad de estandarizar o uniformar, lo cual posibilita una interpretación y análisis sociológico y, por qué no, sociojurídico sin estereotipos o estigmatizaciones.

Se ha olvidado en la pedagogía y en la cotidianidad de lo público el principal pegamento de la sociedad, que lo constituye el principio de la amorosidad y el afecto ${ }^{43}$. A través de la ternura, del afecto, del amor, se aprende mejor y se contagia de ese sentimiento que hace ver al otro como un ser humano, lleno de virtudes, de bondades, y de errores que se pueden remediar o corregir. EI primer pacto se debe basar en el amor, por tanto este acto se convierte en el primer derecho del niño en palabras del poeta Corcuera. Para poder construir sociedad hay que quitar las máscaras, las corazas, y poner a flote esa ética que habita en cada ser y que le permite relacionarse con el entorno y con el otro.

Hay realidades concretas, en las que los niños y jóvenes viven necesidades específicas y conviven con un sistema de dominación, imposición y violencia física, sicológica, simbólica... Y pese a ratificar un sinnúmero de tratados internacionales, la realidad lleva a afrontar un problema de tipo

\footnotetext{
42 Ibíd. pp. 15-16.

43 Ver: Alejandro Cussianóvich. Pedagogía de la ternura. También, Paulo Freire. El atributo cultivable de la "amorosidad".
}

económico en el que familias de estratos socioeconómicos menos favorecidos no alcanzan a suplir la canasta básica, estando por debajo de la línea de necesidades básicas insatisfechas, muchas veces en la línea de pobreza o en la de indigencia (cuyos ingresos mensuales oscilan entre un salario mínimo, medio o una tercera parte de este).

Ante estas realidades, muchísimas familias van en contravía de lo establecido por la OIT respecto a la prohibición de menores de edad en actividades productivas y económicas. Como actores centrales de sus propias vidas, para no entrar en el asistencialismo y cubrir las necesidades básicas de su núcleo familiar, muchos niños y adolescentes trabajan en diferentes labores, no teniendo otra opción que la de aprender y socializarse a través del "trabajo". Ante esta circunstancia han entrado algunas ONG, el sector de la Academia y algunas asociaciones de la niñez y la adolescencia, para que los productos elaborados por estos menores de 16 años tengan la etiqueta de sellos verdes, lo cual certifica la no explotación laboral de este grupo y las ganancias de la comercialización se distribuyen directamente a ellos.

Dicho movimiento se llama Molacnats (Movimiento Latinoamericano de Niños, Niñas y Adolescentes Trabajadores), cuya representación de $\mathrm{NAT}^{44}$ se encuentra también en Colombia.

Los menores de edad asociados en esta iniciativa, que desarrollan labores como la de reciclaje de papel, producen tarjetas elaboradas con valor

\footnotetext{
44 El Proyecto Pequeño Trabajador, PPT, es una organización comunitaria que desde hace 20 años trabaja en la restitución de derechos de los niños, niñas y adolescentes trabajadores y sus familias en el sector de Patio Bonito. El PPT acompaña grupos de menores de edad trabajadores, incentiva y apoya iniciativas económicas solidarias, programas culturales y artísticos; ha diseñado e implementado una apuesta educativa adecuada a la realidad de este grupo poblacional, generando espacios de reflexión sobre el tema en encuentros nacionales e internacionales, donde los mismos menores de edad participan y son protagonistas de la transformación de sus realidades. Información disponible en la página web montada por los niños y niñas del proyecto del movimiento latinoamericano - link Colombia donde se encuentra su catálogo: www.molacnats.org
} 
agregado y otros productos como lámparas, pisapapeles, cuadros, entre otros, que exportan directamente a Europa y que comercializan bajo el sello Comercio Justo (COMERCATO ITALIA). Los promueve particularmente la Red de Maestrías en Derechos Humanos, Infancia y Adolescencia que conforman 19 universidades europeas; a nivel Bogotá se está socializando el tema en la academia en facultades de derecho, ciencias sociales y economía, y se están elaborando estrategias con las grandes superficies para reflejar esta realidad y comercializar los productos en pequeños stands como iniciativas de responsabilidad social empresarial y economía solidaria.

Siguiendo en este eje de violencia, la niñez y la adolescencia hoy en día son protagonistas en la deconstrucción del patriarcado y del machismo hegemónico, repensando la sociedad que están viviendo y estableciendo pautas de comportamiento de no agresión y no violencia con el otro. Estar conscientes de que se puede ser un actor activo y transformador de la realidad social permite construir una lógica incluyente del sano cuidado, del abordaje del cuerpo, del sexo, del género como construcción colectiva desde algunas de las posturas feministas, de colectivos LGBT, de colectivos de derechos humanos y de discursos de algunos hombres asociados en colectivos de masculinidades, abre espacios a través de lenguajes que, además de la igualdad y de la equidad, reconocen a los sujetos en sus situaciones particulares y no siempre al hombre como poderoso, macho, dominante, y a la mujer como sumisa o víctima, ya que hay hombres que son victimizados por las mismas mujeres, o en el caso de la prostitución masculina no son visibilizados porque esto va en contravía de los patrones culturales heredados del patriarcado. Colectivos como el de Hombres y Masculinidades ${ }^{45}$ son un claro ejemplo de esta

45 El Colectivo Hombres y Masculinidades es una organización no gubernamental que desde 1996 adelanta actividades de investigación y capacitación sobre distintos aspectos de género $y$, en particular, temas asociados a la masculinidad. Agrupa a construcción mancomunada e incluyente con la niñez y adolescencia, lo cual permite disminuir la violencia, dar una aproximación e interpretación del cuerpo, del erotismo, de la sexualidad responsable, no sólo en los colegios públicos a nivel distrital y nacional, sino también a otros grupos de personas de ocupaciones y profesiones variadas (Tirado, 2008: 152).

Se ha tenido la tendencia, en esta transversalización de la perspectiva de género, a priorizar las mujeres, y muchísimos hombres hoy en día no se sienten parte activa de esta discusión, porque dentro de la inclusión entra la exclusión, y algunas posturas feministas replican el modelo antagónico de machismo exacerbado, elaborando teorías y discursos en los que no cabemos los hombres. Este enfoque no permite construir colectivamente y asumir el mea culpa como hombres, tratando de crear y consolidar una sociedad más justa, equitativa, incluyente, en los procesos de cambio que se buscan con la política de la perspectiva de género.

Entonces, lo anterior quiere decir que aparecen unos nuevos protagonistas en este proceso, y son los hombres quienes empiezan a preguntarse por su lugar en el mundo una vez las mujeres han reacomodado el suyo. Ante ello, muchos hombres se sienten interpelados y comienzan a reconocer que el tema de género también les compete, porque, igual que las mujeres, se constituyen como hombres también desde esta categorización social.

Sin embargo, y a pesar de que en el mundo el tema de las masculinidades se mueve desde hace más de veinte años, todavía la necesidad de trabajar sobre este aspecto no aparece tan claro como en el caso de las mujeres, lo que no le quita

hombres de distintas experiencias y profesiones, con presencia distrital, nacional e internacional, a través de conferencias, talleres, animación de grupos y actividades académicas. De este modo, el Colectivo ha ido consolidando una experiencia conceptual y metodológica que lo hace un grupo piloto en el posicionamiento de las indagaciones sobre los distintos campos de la masculinidad y en lo que a temáticas de género y diversidad sexual se refiere. www.masculinidadescolombia.com 
pertinencia y urgencia. Esta, ante todo, se refiere al peso que las conductas de los hombres tienen sobre las realidades de violencia doméstica y social que vive el país, así como en los índices de accidentalidad, consumo de sustancias psicoactivas, criminalidad y delincuencia, pandillismo, matoneo escolar, barras bravas, por señalar las vinculadas a dinámicas de agresividad, y por no ampliar con los casos de abandono de las responsabilidades paternas, o las del papel del licor en las experiencias socializadoras de los hombres, sumado al sexo como mecanismo de dominación en el que la mujer es un simple recipiente. Estas realidades transitan por los espacios educativos y formativos, pero allí no se replantean, no se confrontan, no se previenen, porque son funcionales al modelo hegemónico de género, y las instituciones le hacen un flaco servicio.

Traer a colación esta realidad es un propósito que se trazan hombres, jóvenes, adolescentes, niños, sin dejar de lado la participación de la mujer en la construcción de nuevas masculinidades desde la perspectiva relacional de género. Esto quiere decir incorporar un enfoque de responsabilidad que visibilice la necesidad de ocuparnos individual y colectivamente en la deconstrucción del patriarcado, tanto del femenino patriarcal como del masculino.

Esto significa trabajar alrededor de este tipo de preguntas: ¿Cómo lograr que los hombres -y las mujeres- se interpelen por sus identidades desde propuestas de género no-patriarcales? ¿Cómo lograr que, por supuesto, las entidades interpelen desde una nueva perspectiva de género su lógica institucional? ¿Cómo disminuir niveles de violencia masculina tanto contra las mujeres como contra otros hombres, transformando las pautas patriarcales de crianza y socialización? ¿Cómo favorecer en los hombres una conciencia libertaria, contribuyendo a que remuevan de sus vidas los nudos patriarcales que aún los atan a lógicas deshumanizantes de vida? ¿Cómo incentivar a la infancia, a la niñez y a la adolescencia hacia una relación de no violencia y no agresión al entorno, al otro y a sí mismos?

Tal es el tipo de inquietudes que deben salir a consideración, pasando del fuero de lo privado a lo público, cuya construcción de identidad o identidades de género pasa de la vida íntima a inspeccionarse también en la social y en las estructuras institucionales. "Hay que ser menos macho y ser más hombre", lo que quiere decir que hay que ser menos dominante, menos violento, menos alfa, $y$ ser más humano, más afectuoso, más amoroso.

También, son el tipo de cuestiones que deben hacer parte del abordaje conjunto de las nuevas masculinidades, y que propenderán porque se dé un paso adelante en los procesos de liberación de género y su consecuente resignificación y transformación de estereotipos o paradigmas, tal como lo establece la Declaración de Río de Janeiro (abril de 2009) involucrando por igual a hombres, jóvenes y niños en la equidad de géneros, promovido por la Red Menengage ${ }^{46}$.

Si se regresa nuevamente a lo establecido en la Convención de los Derechos del Niño, el concepto socio-jurídico del interés superior del niño no puede entenderse simplemente como una "buena intención", como una frase propia de discursos demagógicos para conmemorar fechas; por el contrario, necesita resignificarse desde los contextos estatales, habida cuenta del sentido de organización que entraña el derecho como creación para la búsqueda de un orden, teniendo como norte el ideal de justicia y no un constructo de fórmulas que se invocan a conveniencia de las directrices del poder.

46 Menengage Global es un esfuerzo de grandes dimensiones globales y locales que está construyendo procesos de comunicación, coordinación, cooperación, acción común sobre los trabajos, para involucrar a los hombres de todas las edades en la construcción de las equidades de géneros. www.engagingmen. org www.menengage.org 


\section{CONCLUSIONES}

a. La historia de los niños, niñas y adolescentes es relativamente nueva; "es una pesadilla de la que hemos empezado a despertar hace muy poco"47, en cuanto esa etapa de la vida se ha entendido como una negación, como una época de vacío por la carencia de responsabilidad y la incapacidad de valerse por sí mismos.

b. La estructura normativa vigente no permite consolidar una perspectiva de eficacia ni aceptación uniforme, ni siquiera en el derecho occidental, donde estados como Estados Unidos se mantienen al margen de la aplicación de la Convención sobre los Derechos del Niño.

c. El interés superior de los derechos del niño es una paradoja en constante circunvolución que, en la práctica, continúa desvirtuando el sentido mismo de humanidad y sociedad.

d. La llamada doctrina de la protección integral consiste en un conjunto de instrumentos jurídicos en el ámbito internacional que transforma la estimación social de la infancia ${ }^{48}$.

\section{REFERENCIAS}

Badinter, E. (1997). XY, la identidad masculina. Bogotá: Ed. Norma.

Cussianóvich, A. (2010, febrero). Evaluación e incidencia de la Convención sobre los Derechos del Niño a veinte años de su aprobación 19892009. En Revista Internacional desde los Niños/as y Adolescentes Trabajadores. (XIV), 18. Lima, Perú.

Fisher, R. (1988). El caballero de la armadura oxidada. Barcelona: Ediciones Obelisco.

47 De Mause, Lloyd. (1994). Historia de la niñez. (2a reimpresión). p. 15. Madrid: Alianza.

48 García Méndez, Emilio y otros. (1998). Derecho a tener derecho. p. 55. Quito, Ecuador: UNICEF.
García, C.I. (2001). La pedagogía del cuerpo como bastión del género. En Revista Nómadas. 14. Bogotá: Universidad Central, Departamento de Investigaciones.

García, C.I. (2002). Edugénero. Aportes investigativos para el cambio de las relaciones de género en la institución escolar. Bogotá: Universidad Central, Departamento de Investigaciones.

García, C.I., y Ruiz, J.O. (2009). Masculinidades, hombres y cambios. Manuales de trabajo. Bogotá: Diakonía.

Gilmore, D. (1994). Hacerse hombre. Concepciones culturales de la masculinidad. Barcelona: Ediciones Paidós.

Gómez, F. y García, C.I. Masculinidades y violencia en Colombia. www.masculinidadescolombia.com

Huertas, R., Ruiz, J.O. y Feliciani, S. (2009). De machos a hombres: violencia de género y desplazamiento forzado. Bogotá: ACNUR, AECID y Colectivo Hombres y Masculinidades, Promotoría juvenil Campaña Lazo Blanco.

Lacecla, F. (2004). Machos sin ánimo de ofender. Fernando Borrajo (Trad.). Madrid: Editorial Siglo XXI.

Liebel, M. (2010, febrero). Derechos: significados para niños y niñas en diferentes contextos sociales y culturales. En Revista Internacional desde los Niños/as y Adolescentes Trabajadores (XIV). 18. Lima, Perú.

Olavarría, J. (2001). Hombres, identidades y violencia. Chile: FLACSO.

Ruiz, J.O. Cuando el género tiene la edad de lo joven y no por eso es mejor. www.masculinidadescolombia.com

Ruiz, J.O. Los hombres en las estadísticas colombianas. www.masculinidadescolombia.com 
Ruiz, J.O. Los niños están siendo víctimas de la hombría. www.masculinidadescolombia.com

Ruiz, J.O. Ser hombre es un factor de riesgo. www. masculinidadescolombia.com

Save the Children. (2006). El derecho a la participación infantil de los niños, niñas y adolescentes en situación de riesgo: menores no acompañados, niños y niñas afectados por conflictos armados y trabajadores infantiles. Madrid.

Schibotto, G. (2010, febrero). Espacio y participación. En Revista Internacional desde los Niños/as y Adolescentes Trabajadores (XIV). 18. Lima, Perú.

Thomas, F. (1997). Conversación con un hombre ausente. Bogotá: Arango Editores.
Tirado Acero, M. (2008). Comercio sexual. Tesis Doctoral en Sociología Jurídica e Instituciones Políticas. Bogotá: Universidad Externado de Colombia, Facultad de Derecho.

Tirado Acero, M. (2010). Comercio sexual. Una mirada desde la sociología jurídica. Lima, Perú: Instituto Internacional de Derecho y Sociedad.

Viveros, M. (2002). De quebradores y cumplidores. (1a. ed.). Bogotá: CES. Universidad Nacional. Fundación Ford. Profamilia Colombia.

Viveros, M. y Garay, G. (Comps.). (2001). Cuerpo, diferencias y desigualdades. Bogotá: CES/UNAL. 